\title{
Three Manufacturing Strategy Archetypes - A Framework for the UK Aerospace Industry
}

\author{
T Greswell, S Childe, R Maull \\ Manufacturing and Business Systems, University of Plymouth, \\ Drake Circus, Plymouth, PL4 8AA, UK, Tel: 44-1752-232546, \\ Fax: 44-1752-233505,Email: tgreswell@plym.ac.uk
}

\begin{abstract}
The paper reports on an aspect of work carried out into manufacturing strategy in the UK aerospace industry. This paper concentrates on the development of three manufacturing strategy archetypes and of a framework to describe the potential use of these archetypes within the UK aerospace industry. The paper describes the changing requirements of the industry when considering manufacturing strategy. The paper includes the development of the archetypes using systems theory, and reports on the contribution made to the field of manufacturing strategy making.
\end{abstract}

\section{Keywords}

Manufacturing strategy, UK aerospace industry, archetypes

\section{INTRODUCTION}

Manufacturing strategy is a powerful concept that enables organisations to make optimum use of the manufacturing capabilities within their people, processes and technology dimensions, to support business strategy and develop new markets. The concept can be traced back to Skinner's seminal paper (1969) which described the use of manufacturing as a competitive weapon, as opposed to a function that is passive to its competitive environment. The UK aerospace industry has changed and still is changing dramatically to adapt to the competitive environment. This has changed the way aerospace organisations approach and perceive operations management and how to achieve competitive advantage 
through manufacturing competencies. The industry has several unique characteristics, which are a result of the industry's evolution, products and technologies. The objective of the paper is to describe the development of three manufacturing strategy archetypes and the subsequent use of the archetypes within one case study.

\section{CHARACTERISTICS OF MANUFACTURING WITHIN THE UK AEROSPACE INDUSTRY}

The past decade has been turbulent for the industrial base within the UK as a whole. The UK aerospace has gone through a major restructuring programme from small component suppliers through to the prime contractors. In the defence sector, contracts are awarded on a fixed price basis as opposed to the traditional cost plus contracts that were enjoyed previously. Aerospace companies have suffered from over capacity with a shrinking market. This challenge has produced an aerospace industry that has recognised the importance of improving the value chain through manufacturing. These organisations are predominantly becoming less functional, with a mixture of projects, processes, and disciplines.

\section{MANUFACTURING STRATEGY}

The work reported in this paper critically evaluated the use of current manufacturing strategy methods within the industry and gathered empirical evidence from three initial case studies in the aerospace industry. This evidence suggested that current manufacturing strategy methods required development to enable the industry to meet the challenges of globalisation, concurrent engineering and the move to a mixture of business process, project focused and functional organisation. Three manufacturing strategy archetypes were identified from the literature by Whittle et al (1994).

Systems theory was identified as a suitable medium by which to describe and develop the three archetypes. This would ensure a frame of reference throughout the research to provide a firm link with business processes and business process focused organisations through systems concepts. Checkland and Scholes' (1990) soft systems methodology was used as the learning mechanism, cycle one of which is presented in this paper.

\section{THREE MANUFACTURING STRATEGY ARCHETYPES}

The manufacturing strategy archetypes evolved from three archetypes initially presented by Treacy and Wiersema (1995) as operational excellence, product leadership and customer intimacy. These have been described by Whittle et al (1994) as: the market led / customer-focused approach, the best practice approach, 
and the knowledge based approach. A summary of the three manufacturing strategy-making systems is included in table 1 .

Table 1 Comparison of three archetypal manufacturing strategy making systems

\begin{tabular}{|c|c|c|c|}
\hline & $\begin{array}{l}\text { market led/customer } \\
\text { focused }\end{array}$ & best practice & knowledge based \\
\hline World-view & $\begin{array}{l}\text { manufacturing companies } \\
\text { must satisfy the demand of } \\
\text { their customers and markets } \\
\text { to be competitive }\end{array}$ & $\begin{array}{l}\text { manufacturing companies } \\
\text { must be on a par with } \\
\text { their competitors to be } \\
\text { competitive }\end{array}$ & $\begin{array}{l}\text { The knowledge created } \\
\text { and held within an } \\
\text { organisation is its greatest } \\
\text { strategic asset }\end{array}$ \\
\hline Inputs & $\begin{array}{l}\text { customer requirements, } \\
\text { marketing information, } \\
\text { business objectives } \\
\text { order winning and } \\
\text { qualifying criteria, product } \\
\text { family data } \\
\text { manufacturing performance } \\
\text { data on the key wining and } \\
\text { qualifying criteria }\end{array}$ & $\begin{array}{l}\text { current industrial } \\
\text { benchmark information, } \\
\text { current manufacturing } \\
\text { systems made up of } \\
\text { people, processes and } \\
\text { technology }\end{array}$ & $\begin{array}{l}\text { Business needs, current } \\
\text { competitive profile, future } \\
\text { competitive profile, skills } \\
\text { and knowledge audit, }\end{array}$ \\
\hline Output & $\begin{array}{l}\text { design of the manufacturing } \\
\text { system to support order } \\
\text { winners and order qualifiers } \\
\text { to align with customer } \\
\text { expectations depending on } \\
\text { price, quality, delivery } \\
\text { reliability and flexibility } \\
\text { action plan }\end{array}$ & $\begin{array}{l}\text { change to the } \\
\text { manufacturing } \\
\text { organisation [people, } \\
\text { processes and technology] } \\
\text { required to move the } \\
\text { organisation to becoming } \\
\text { the benchmark }\end{array}$ & $\begin{array}{l}\text { Manufacturing strategy - } \\
\text { identifies current } \\
\text { capabilities / } \\
\text { competencies and future } \\
\text { requirements for } \\
\text { manufacturing } \\
\text { Team and individual } \\
\text { learning }\end{array}$ \\
\hline Mechanisms & $\begin{array}{l}\text { Business process re- } \\
\text { engineering, Total quality } \\
\text { management, Quality } \\
\text { awards, Manufacturing } \\
\text { audits, European } \\
\text { Foundation for Quality } \\
\text { Management, Hills } \\
\text { manufacturing strategy } \\
\text { (1985) methodology, Platts } \\
\text { and Gregory (1994) } \\
\text { methodology, Competitive } \\
\text { profiling }\end{array}$ & $\begin{array}{l}\text { Benchmarking, } \\
\text { Identification of best } \\
\text { practice, European } \\
\text { Foundation for Quality } \\
\text { Management, } \\
\text { Manufacturing audits, } \\
\text { Gap analysis, } \\
\text { Performance measures, } \\
\text { World class } \\
\text { manufacturing, Business } \\
\text { process re-engineering to } \\
\text { achieve step change or } \\
\text { radical change, Total } \\
\text { quality management - } \\
\text { incremental improvement }\end{array}$ & $\begin{array}{l}\text { Skills audits } \\
\text { Technology audits } \\
\text { Process audits } \\
\text { Manufacturing audits } \\
\text { The learning organisation } \\
\text { Concurrent engineering }\end{array}$ \\
\hline
\end{tabular}

In this research each archetype was characterised using systems concepts in order to define the boundaries and key parameters for each. The benefit of developing the archetypes in this way is to enable the operations management practitioner to determine which current archetype is predominant within their approach. This in turn enables the practitioner to identify if any other facets in the approaches that are not currently predominant would be suitable for their manufacturing operation to enhance the value chain, or to determine whether a transformational view incorporating all of the archetypes is beneficial. It is 
interesting to consider the following when taking the archtypical view of manufacturing strategy:

1. Does each manufacturing strategy archetype have a preferred use within different parts of an organisation, i.e. whether the manufacturing operation is process, function or project based, or a mixture?

2. Do the archetypes sit within a hierarchy of manufacturing strategies?

3. Can each archetype be used singly to provide the organisation with maximum benefit or is an integrated approach more beneficial?

Each archetype is described in systems terms, to enable a comparison to be made between the three manufacturing strategy making systems identified. Each strategy making system is described using a root definition, i.e. a statement in the format 'a system to do $\mathbf{x}$ by means of $\mathbf{y}$ in order to achieve $\mathbf{z}$ '.

\subsection{The customer focused/market led manufacturing strategy making system}

A root definition for the customer-focused/market led market led manufacturing strategy-making system is: "A system to produce a manufacturing strategy, which enables the alignment of the manufacturing organisation to support the business strategy, by means of identifying relevant product groups, identifying order winners and order qualifiers for each product group and aligning the manufacturing organisation as necessary, in order to achieve customer satisfaction and through customer satisfaction, competitive advantage.'

The system is characterised by a focus on the customer's needs as the primary driver for the identification of order winners and order qualifiers. These may include quality, for example conformance to requirements, delivery reliability for example short lead-times, delivery flexibility for example to fit in with a customers JIT philosophy, and product variability. These characteristics are fed into the key decision areas as defined by Hayes and Wheelwright (1984) to enable the alignment of the manufacturing organisation to the customer requirements. This is described by Hill (1984) as the infrastructure and structure of manufacturing and includes aspects such as process choice.

This system aligns to the customer intimacy archetype as described by Treacey and Wiersema (1995). This is underpinned by the philosophy that getting close to the customer and meeting and or exceeding customer requirements will enable the building of a sustainable competitive advantage. This system has been characterised by Whittle et al (1994) as the 'Outside-In' approach to manufacturing strategy. The organisation has predominately an outward looking perspective and keeps a sharp eye on the market requirements to ensure the manufacturing organisation is aligned to support those requirements. Due to this 
alignment, marketing is a key stakeholder within this archetype and problems may occur if the marketing department has a different view of what manufacturing should deliver compared to the views of manufacturing. The importance of the customer is key, with the quality systems and business processes being aligned to the customer requirements.

\subsection{The best practice manufacturing strategy making system}

A root definition for the Best Practice strategy making system is: 'A system to produce a manufacturing strategy by identifying and implementing current best practice manufacturing philosophies and techniques by means of competitive benchmarking and the business excellence models to improve the competitive position of the organisation'

This system is characterised by developing people, process and technology excellence in order to delivery operational excellence. The underlying principles focus on an organisation striving to become the benchmark for their current industry. This is achieved by emulating best practice, identifying the gaps within current manufacturing dimensions concerning people, process and technology, and driving through changes which will enable the organisation to be on a par with the best in the industry. This is characterised by Camps' work (1989) as the 'search for best practices, which cumulatively lead to superior performance'. The Best Practice archetype corresponds to Treacey and Wiersemas' (1995) operational excellence, which is based upon the philosophy that achieving operational excellence will enable the building of a sustainable competitive advantage.

\subsection{The knowledge based manufacturing strategy making system}

A root definition for the knowledge based manufacturing strategy making system is: 'A system to produce a manufacturing strategy which identifies, develops and nurtures technological, process and human core competencies within the manufacturing system by means of developing a learning organisation in order to stay ahead of the competition by developing new markets and directions'.

This system is still in the cradle as regarding its evolution but appears to be characterised by focusing on developing competencies around the aspects of people, process and technology, which are difficult for other organisations to replicate. As a strategy it focuses on the philosophy that by identifying and developing core competencies which are difficult to replicate it will open up new markets which will have high barriers to entry for other competitors.

This will lead to a sustainable competitive advantage, as no other organisation will be able to match the critical characteristics of the organisation, that are 
intrinsic within its core competencies. This is described by Prahalad and Hamel (1990), Hayes and Pisano (1994) and Teece, Shuen and Pisano (1997).

The system corresponds to the product leadership Treacey and Wiersema (1995) archetype, which is characterised by the philosophy that by achieving product leadership will enable the building of a sustainable competitive advantage.

\section{CASE STUDY OF THE USE OF THREE MANUFACTURING STRATEGY ARCHETYPES}

The case study is a complex organisation that is split along three main dimensions within the value chain. These include customer projects, internal supply and functions. Internal supply provides kit sets and parts to the customer projects and the functions are responsible for people and process excellence. Due to the complexity of the business and the different requirements for each customer project, developing a manufacturing strategy has taken several streams. The outcome of the manufacturing strategy has emerged as three levels which map onto the three manufacturing strategy archetypes described earlier.

The strategy making that occurred in this case, identified the core competencies that were required within each location of the organisation, which were mapped onto future market requirements to provide a tiering system throughout the organisation. Each manufacturing tier corresponds to a tier within the value chain. The make or buy element of manufacturing strategy was built around the identification of current competencies and which of these would be kept in house as strategic competencies. The above slots into the knowledge based manufacturing strategy archetype.

The market led / customer focused manufacturing strategy archetype was linked to the customer projects manufacturing processes. Manufacturing strategy making for a major new project used the concepts of order winners and order qualifiers to align the new manufacturing processes required to deliver the performance required by the customer. Delivery reliability was identified as key and the manufacturing system was developed using lean manufacturing as the philosophy.

The best practice manufacturing strategy archetype was evident throughout the manufacturing organisation. The business excellence model was used to identify key business enablers which included the manufacturing process, this incorporated the continuous improvement philosophy, and the manufacturing engineering process which incorporated a journey from learner to world class for each manufacturing business. Each manufacturing business reports on their 
progress monthly which enables the sharing of best practice throughout the organisation.

The three archetypes appear to fall into a manufacturing strategy hierarchy. The knowledge-based approach was used to set the main direction for each manufacturing tier within the business. The market led/customer focused approach was used within individual projects to align products to the customer requirements. The best practice approach was used within internal supply to continuously strive for greater efficiency.

\section{DISCUSSION AND FUTURE RESEARCH}

The examples described above map onto the three archetypes. The archetypes are useful in providing the operations management practitioner with a framework to provide focus. The introduction of archetypes may be useful when formulating a Manufacturing Strategy to provide other views. The experience of the case organisation is that managing the complexity within the manufacturing process and ensuring the organisation gains the maximum benefit from the manufacturing organisation from the dimensions of people, processes and technology is very difficult. The three archetypes provide a focus for the organisation and provide the practitioner with reference points and other directions if appropriate. To answer the questions posed at the beginning of the paper.

1. It appears from the case study that the three manufacturing strategy archetypes do have a preferred use within the different parts of the case organisation, however there is overlap between the three archetypes that would be expected.

2. The case study suggests that the three archetypes sit within a hierarchy, however more case studies would be needed to substantiate this view.

3. It would appear from the evidence provided from the case study that all three archetypes provide each part of the organisation with benefits. However the benefits of using an integrated approach are also evident from the performance of the overall organisation.

\section{REFERENCES}

Camp, C. (1989) Benchmarking: the search for best practices which lead to superior performance - parts 1 to 5, Quality Progress, Jan-May

Checkland, P and Scholes, J (1990) Soft systems methodology in action Wiley and sons UK

Hayes RH and Pisano GP (1994) Beyond world class manufacturing - the new manufacturing strategy Harvard Business Review Jan-Feb. pp 77-86. 
Hayes, R and Wheelwright, S (1984) Restoring our competitive edge: competing through manufacturing Collier Macmillan NY

Hill $\mathrm{T}$ (1984) The strategic management of the manufacturing function Macmillan UK

Mills J Platts K Gregory M (1995) A framework for the design of manufacturing strategy processes International Journal of Operations and Production Management 15(4) 17-49

Prahalad, C.K. and Hamel, G. (1990) The Core Competence of the Corporation, Harvard Business Review, Vol. 68, May-June, pp. 79-91

Skinner W (1969) Manufacturing - the missing link in corporate strategy Harvard Business Review May-June pp 136-45

Teece DJ, Shuen A, Pisano G (1997) 'Dynamic capabilities and strategic management' Strategic Management Journal 18 (7)

Treacy and Wiersema (1995) Discipline of market leaders Harper Collins

Whittle et al (1994) Regenerating competitive performance - strategy of capability building? EurOma conference on operations strategy and performance Churchill college, University of Cambridge June 27-29

\section{BIOGRAPHY}

Tammi Greswell is a research assistant at the University of Plymouth currently employed on a grant developing a methodology for process based change within Small to Medium Sized Manufacturing Enterprises

Dr Childe is a joint leader (with Dr Maull) of the Manufacturing and Business Systems research group at the University of Plymouth. His research interests include production management and manufacturing systems, intervention methodologies, implementation, and human aspects. He has held various research grants including currently a methodology for the re-engineering of business processes. He is the author of An introduction to Computer Aided Production Management and a member of IFIPs working group 5.7 on computer aided production management.

Dr Roger Maull is a joint leader (with Dr Childe) of the Manufacturing and Business Systems research group at the University of Plymouth. His research interests are based within systems theory. Topics include Business Process Reengineering, systems and enterprise modelling, all types of operations and production management TQM, and approaches to organisational culture analysis. $\mathrm{He}$ is a principal investigator on one EPSRC, one EPSRC IMI and a coinvestigator on an ESRC Innovation research project. 